\title{
One Typology for a Big Word: Office of Diversity
}

\begin{abstract}
Architecture's original project was the invention of interiority, an enclosed area delimited from its context and made available for a narrowly defined public, function, and meaning. This original project was expanded during the Enlightenment with the concept of type as a method for producing architecture and establishing social institutions for molding subjectivities. This quest for interiority has reached its completion with world capitalism and its associated complexes, which, as Michael Hardt and Antonio Negri have argued, are an interior without any possible or imaginable outside. In response to this condition, this essay argues that the original project of architecturethe conception and design of interiority-needs to be replaced by a new one: the conception and design of openings. To demonstrate this, I have assembled Typologies for Big Words, a series of projects that redefines the concept of type through a selection of building and landscape types proposed as openings within this global interior. Using Byung ChulHan's portrayal of contemporary society as an achievement society occupied by achievement-subjects, I present one of these projects as an example, Office of Diversity, as an opening for the production of nonparadigmatic subjectivities.
\end{abstract}

Keywords: interiority, type, office, diversity, achievement society

Correspondence Address: Sergio Lopez-Pineiro, Department of Landscape Architecture, Harvard Graduate School of Design. 48 Quincy Street, Cambridge, MA 02138, USA. Email: lopezpineiro@gsd.harvard.edu 
Architecture has been interiority.

\section{The Project of Interiority}

Interiority should not be mistaken for indoor space. Instead, interiority refers to the act of bounding space from its context. Arguably, "the distinctive quality of any man-made place is enclosure" (Norberg-Schulz, 1980, p. 58). While this statement by Christian Norberg-Schulz is not self-evident, it points to a quality invariably found across cultures that defines a likely universal understanding of outside-inside relationships.

For example, the Romans used the concept of locus to define the relationship between a concrete location and the buildings in it. As described by Aldo Rossi (1982), the site "was governed by the genius loci, the local divinity, an intermediary who presided over all that was to unfold in it" (p. 103). The locus signifies a singular space as it "emphasizes the conditions and qualities within undifferentiated space" (Rossi, 1982, p. 103). Different versions of the expression genius loci and the attitude toward this "spirit of place" can be found in most cultures. While this condition does not necessarily have to be rendered physical as an enclosure, it does convey an extension and, thus, a similar outside-inside relationship.

In her analysis of the relationships between Roman architecture and rhetoric, Gretchen Meyers states that

unlike the Greek process, which involves selecting concepts or images from a mental sore of sequentially arranged items, the Roman concept of memory invites the user to enter a physical space (locus) within the mind and recall the idea or image associated with that space. (Meyers, 2005, p. 70)

More relevant to the arguments that will be made later in this article is the fact that "Roman rhetorical treatises indicate that physical places, specifically architectural ones, provide the ideal form of locus to house ideas for memorization or arrangement within a speech" (Meyers, 2005, p. 69). The Roman rhetorical technique for using architecture to anchor memory indicates how deeply rooted within the Western tradition is the use of architecture by individual citizens as the framework to communicate and describe their personal ideas.

This quest for interiority can be more broadly represented with, for example, Charles Eisen's well-known engraving of a primitive hut as an allegory of architecture. This frontispiece to the 1755 edition of Marc-Antoine Laugier's Essai sur l'Architecture shows the muse of architecture pointing to humanity's first structure as a roofed space. 
The focus on the conception and imagination of interiority is also present in landscape architecture, amongst other design disciplines of the built environment. In his article A Built Landscape Typology, Patrick Condon builds upon the work of René Dubos, Jay Appleton, and George Frazer, to postulate that

taken together, the works of Dubon, Appleton, and Frazer support the proposition that the forest and the clearing, understood as a dialectical pair, are the archetypal landscape space foundation upon which the edifice of a designed landscape space typology can be created. (Condon, 1994, p. 89)

Furthermore, he speculates that the clearing in the forest is the most basic room ever designed. A clearing, an area free of trees in the woods, is a distinctly defined, bounded, and contained space that establishes clear boundaries between its interior spaces and the outside world. While clearings occur naturally without human intervention via ecological processes, they can also be constructed by design.

Another essential landscape type is worth noting to emphasise the relevant presence of interiority in landscape architecture's original aims. The Latin expression hortus conclusus was conceived to describe the paintings of enclosed gardens in Christian art from the Middle Ages. This fundamental type of garden, typically used in depictions of the Virgin Mary, often symbolised purity and virginity through its enclosure from the outside world. A kind of hortus conclusus is, for example, Athanasius Kircher's engraving Topographia Paradisi (Topography of the Earthly Paradise) from his book Arca Noë. While the expression hortus conclusus depicts gardens of the Christian tradition, enclosed gardens are a foundational type of garden of every culture.

\section{Building Types as Interiorities}

The concept of type was theoretically articulated following the rational philosophy of the Enlightenment. However, the concept of type also furthered architecture's original quest for interiority by unleashing interiority's power for constructing specific subjectivities. Over the last couple of centuries since the publication of Quatremère de Quincy's Dictionnaire Historique de l'Architecture in 1832, many authors have elaborated competing definitions of architectural type.

In this article, I rely on Rafael Moneo's analysis and overall historical account of the concept of type as it appeared in his well-known 
essay On Typology (Moneo, 1978). In my view, it summarises the most widely shared canonical understandings of this architectural concept. In simple terms, a type is "a concept which describes a group of objects characterised by the same formal structure" (Moneo, 1978, p. 23). This concept is fundamental to architecture because, as he argued, architecture "is not only described by types, it is also produced through them" (Moneo, 1978, p. 23). This harmless sentence, which has received no attention because most architects and designers of other related fields of the built environment agree with it without much hesitation, points to a critical confusion. While the producers of architecture Moneo refers to are the architects, it is not clear who the describers of architecture ultimately are in this text. Granted, the writing of the sentence in passive voice does not help clarify this question. Moneo states and the first few images of vernacular settlements and villages included in the article suggest that, as a formal structure, a type is "intimately connected to reality" (Moneo, 1978, p. 24). However, since the article focuses on types as mechanisms conceived theoretically for and used by architects, the reader quickly assumes that the describers of architecture must also be architects.

Several authors have wrestled addressing the tension between the description and production of types or, in other words, between the social and disciplinary realms within which types ultimately exist. For example, Aldo Rossi (1982) unambiguously pointed out the limitations that arise if one considers the description of such experiences in his influential book The Architecture of the City.

Thus, the concept that one person has of an urban artifact will always differ from that of someone who "lives" that same artifact. These considerations, however, can delimit our task; it is possible that our task consists principally in defining an urban artifact from the standpoint of its manufacture. (Rossi, 1982, p. 33)

While Rossi presents an argument that is coherent with the morphological method he laid out in his book, it is fair to say that his statement encapsulates the difficulties faced by most theoreticians and writers of this matter. Ultimately, most definitions of the concept of type have been limited to its role in architecture production.

A more comprehensive description of the concept of type requires admitting that these formal structures are simultaneously disciplinarily and socially produced and described. In particular, building types are not only formal structures. In the public's mind, these spaces are also physical manifestations of social institutions (be it the home, the school, the place of prayer, etc.) to cater to or 
construct particular subjectivities. ${ }^{1}$ Several authors have pointed this out, but the most well-known analysis on this matter is Michel Foucault's studies of modern institutions and their role in constructing modern society (Foucault, 1979). However, I am using the term social institution here in the same way that Michael Hardt and Antonio Negri have used it to describe the construction method of modern subjectivities:

The institutions provide above all a discrete place (the home, the chapel, the classroom, the shop floor) where the production of subjectivity is enacted. In the course of a life, an individual passes linearly into and out of these various institutions (from the school to the barracks to the factory) and is formed by them. The relation between inside and outside is fundamental. Each institution has its own rules and logics of subjectivation: "School tells us, 'You're not at home anymore'; the army tells us, 'You're not in school anymore."' Nevertheless, within the walls of each institution, the individual is at least partially shielded from the forces of the other institutions; in the convent, one is normally safe from the apparatus of the family, at home one is normally out of reach of the factory discipline. This clearly delimited place of the institutions is reflected in the regular and fixed form of the subjectivities produced. (Hardt \& Negri, 2000, p. 196)

For this reason, while architects do not ultimately require this social aspect to activate the mechanism of type-form to produce architecture, architecture is nevertheless described as typeinstitution by the public through their social perceptions and experiences. Building types, then, are mechanisms with a dual nature. They have a formal-institutional duality: building types are formal structures and physical manifestations of social institutions depending on whether architecture is being described or produced. As institutions, building types are interiorities that reify paradigmatic socio-cultural practices and, as a result, contribute to the construction of specific subjectivities. ${ }^{2}$

\footnotetext{
"I am not using the term "social institution" here as a placeholder for function or program. Therefore, I am not taking a functionalist approach to the concept of type. Instead, I am pointing out the institutional character that is inherent to any building type and, therefore, I am emphasising the relationship that exists between building types and the subjectivities associated with each of these particular institutions.

2 The argument I have laid out here has focused exclusively on the articulation of type, in general, and building type, in particular. However, landscape types, as formal structures, also abide by similar principles.
} 


\section{A World That Knows No Outside}

Theorists have long argued that there is no space available beyond world capitalism and its associated complexes as the prevailing global system of organisation. Hardt and Negri seem to have summarised this best, arguing that "in its ideal form there is no outside to the world market: the entire globe is its domain" (Hardt \& Negri, 2000, p. 190). The development of this condition has triggered specific cultural shifts, resulting in new spatio-temporal logics and sensibilities (Harvey, 1989; Jameson, 1991).

Broadly, the origins of this assessment can be found in the foundations of the philosophical discourse of Postmodernism as defined by the works of Michel Foucault and others with their criticism and re-appraisal of the socio-cultural discourses and practices developed between the Enlightenment and Modernity. Specifically, this condition without an outside was synthetically captured by Jacques Derrida's in the now-famous sentence from his book Of Grammatology "il n'y a pas de hors-texte," and (mis)translated by Gayatri Chakravorti Spivak's as "there is nothing outside of the text." Spivak's literary translation, which she immediately followed with the literal "there is no outside-text" (Derrida, 1974, p. 158) for purposes of clarity, has caused nevertheless multiple discussions and disagreements. Despite these misinterpretations, Spivak's choice of words was an apt one because it pointed to the essence of these thinkers' argument: the inherited socio-cultural discourses and practices had produced an interiority that did not account for the existence of an outside-and, consequentially, the possibility of counter-discourses and counter-practices.

A wide variety of authors later furthered this understanding, signaling that Derrida's textual framework could be applied to every other realm and demonstrating that the inherited collective conscience lacked an outside in multiple different fields. Within the field of architecture, Elizabeth Grosz has used the work of Bergson, Deleuze, Irigaray, and others to address this philosophical question and show how this condition of interiority can be addressed and subverted with the medium of architecture itself, space (Grosz, 2001).

More recently, Michael Hardt and Antonio Negri (2000) have analyzed in broad socio-cultural and politico-economic terms the absence of outside in their book Empire. As they succinctly stated, the world defined by the current regime is a place where "there is no more outside" (Hardt \& Negri, 2000, pp. 186-190). They use "empire" as a concept that allows them to think theoretically about the current world order. "The concept of Empire is characterized fundamentally by a lack of boundaries: Empire's rule has no limits." 
This condition of a limitless regime occurs spatially ("rules over the entire "civilized" world"), temporally ("a regime with no temporal boundaries and in this sense outside of history or at the end of history"), and socially ("object of its rule is social life in its entirety, and thus Empire presents the paradigmatic form of biopower") (Hardt \& Negri, 2000, pp. xiv-xv). While "empire" is a concept to theorise the current regime, its capitalist foundations operate with a similar appetite: "The capitalist market is one machine that has always run counter to any division between inside and outside. It is thwarted by barriers and exclusions; it thrives instead by including always more within its sphere" (Hardt \& Negri, 2000, p. 190).

In the 1970s, the Italian design group Archizoom already seemed aware of this condition as they argued that cities are a selfenclosed reality. They are a continuous capitalist phenomenon without exterior:

The carrying out of a social organization of labor by means of Planning eliminates the empty space in which Capital expanded during its growth period. In fact, no reality exists any longer outside the system itself: the whole visual relationship with reality loses importance as there ceases to be any distance between the subject and the phenomenon. (Archizoom Associati, 2006, p. 178)

In addition to this awareness, they also realised that "the urban phenomenon is the weakest point in the whole industrial system" (Branzi, 2006, p. 176). Thus, in response to this overall assessment, Archizoom designed No-Stop City, a visionary critique toward urbanisation and its constitutive elements. No-Stop City is an infinite, interior, white, and gridded space occupied by various homogeneously distributed architectural components. Archizoom's city is a never-ending sublime environment of epic dimensions portraying the unprecedented delightful horror of capitalist space. The fully interiorised world presented by Archizoom in No-Stop City served as an acute prophecy of the present moment in time and showed the fulfillment of architecture's original project-the conception and design of interiority.

For clarity purposes, it is necessary to note that Archizoom's NoStop City operates at two levels of interiority. Firstly, these are indoor spaces without an external image as no elevations of this interior space are provided. This interiority can be understood as physically self-evident and, ultimately, superficial. Secondly, this project proposes an immediate space where the distance between the subject and the urban phenomenon, as described in their text, has disappeared. "The city no longer "represents" the system, but 
becomes the system itself, programmed and isotropic, and within it the various functions are contained homogeneously, without contradictions" (Branzi, 2006, p. 178). Ultimately, this lack of distance is masterfully expressed architecturally through an inescapable interiority. Therefore, No-Stop City is not an architectural milestone because it presents a never-before-seen interior space. But because Archizoom unambiguously collapsed both conditions of interiority, the physical and the capital.

Archizoom's originality revealed that architecture's quest for interiority matched capitalism's appetite for ever-growing maximisation and optimisation. Archizoom's work foresaw the challenges that architecture would encounter when completing its original project after a historical era of approximately two millennia and anticipated the current conundrum faced by designers of the built environment when architecture and other parallel disciplines have run their course. The question that arises after Archizoom's work is the same one that emerges after any revelation: What to do next?

\section{A New Mission}

At this moment in time, architecture's original mission-the conception and design of interiority-must be flipped. What "a world that knows no outside" now requires from the design disciplines of the built environment are openings within the prevailing system to distance the subject from the urban phenomenon. In opposition to its old mission, architecture's new mission can be summarised as the conception and design of openings. However, the initial clarity of this mission is complicated by the contemporary collapse of the institutional loci. As Hardt and Negri have insightfully argued,

today the enclosures that used to define the limited space of the institutions have broken down so that the logic that once functioned primarily within the institutional walls now spreads across the entire social terrain. Inside and outside are becoming indistinguishable." (Hardt \& Negri, 2000, p. 196)

In other words, the type's formal-institutional duality is now obsolete.

Therefore, architecture's new mission-the conception and design of openings - not only requires reimagining building and landscape types but, most fundamentally, replacing the type's obsolete formal-institutional duality. The types to be reimagined are no longer loci within the fabric of the prevailing global system, but, rather, tears within it, distances between the subject and the urban 
phenomenon that occupies everything and denies the possibility of an alternative reality. In this context, buildings and landscapes cannot be individual structures amongst others with similar formal characteristics. They cannot reify patterns; they must be voids. The world might know no outside, but it needs gaps or holes as opportunities for non-paradigmatic subjectivities. These openings are spaces for everyone and everything that is not accepted by the system and is characterised as unwanted, strange, different, inconceivable, unimaginable, or marginal. Consequentially, the formal-institutional duality is replaced by a duality that can be expressed as void-opening.

Several questions might arise as a consequence of this process. In particular, the reader might be asking that if a formal structure no longer belongs to a group of objects with similar formal characteristics, how can it express a type? Also, if a formal structure can no longer describe an institutional locus, is it an expression of a type? The responses to these two questions would differ in aspect but are the same in essence. The type that I am proposing is no longer that of a formal structure amongst others with similar characteristics able to define institutional loci. The new kind of type offered here is that of a void as an opening for the emergence of non-paradigmatic subjectivities.

\section{Typologies for Big Words}

Typologies for Big Words is a series of projects reimagining traditional building and landscape types as openings within the interiority of the current global system. These new spatial types are propositions for openings to the socio-cultural and politico-economic system. They have a diametrically opposite mission to the one of the train station, the triumphal arch, the cathedral, or the opera house. These projects are meant to be illustrations and provocations of how the world could operate (eventually or right now). They are allegories and fantasies intended to be absurd, funny, engaging, and frightening. They represent a search for a space that can lead to a new innocence and a new sublime. These projects redesign traditional typologies (factory, office, mausoleum, etc.) as holes opening up in contemporary society's big words (ecology, democracy, capitalism, etc.). Consequently, each project is named after a spatial type and a big word, such as Factory of Ecology or Museum of Capitalism.

Each typology for a big word comprises an inseparable pairing of a design proposal and a theoretical essay. These two pieces of work are not independent of each other: text and figures (drawings and images) go along each other, hand in hand. The figures illustrate the 
theoretical argument as much as the essay illuminates the rationale behind the design proposal. Typologies for Big Words mixes each design proposal with its theoretical essay, making them flow in parallel to each other.

Contrary to the customary structure of most design monographs, projects in this book are not presented via a theoretical essay followed by a design proposal. Typologies for Big Words is not a monograph. Instead, these projects are the medium I have used to construct an intellectual position defined by a distinct spatial and aesthetic sensibility - a method of working, then, that involves designing a cohesive series of projects. The output of this working method is Typologies for Big Words, a book that must be understood as both a method and a product rather than as a compendium or catalog.

Postmodern architecture was concerned with questions of language and discourse. In other words, it was connected, influenced by, and resonated with the early understandings of the outside, as expressed by Derrida, Deleuze, and others. Typologies for Big Words is not concerned with these questions nor with these approaches. It imagines openings by reimagining building and landscape types through poetic rather than syntactic or semantic means to envision spaces that address current socio-cultural sensibility. This series of projects attempt to reduce spatial requirements (functional or institutional) while searching for the spatial and formal precision that can express this sensibility. Consequently, these projects do not aim to satisfy typological expectations (functional or institutional) but to ground spaces for new uncategorised subjectivities.

\section{Office of Diversity}

As an example of this approach, I present here Office of Diversity, one of the series' projects. In opposition to the standard definition of the office as a space structured for non-physical labor carried out by hired workers in pursuit of a commercialisable product, this office is a seemingly post-political space where autonomous workers, as "entrepreneurs of themselves" (Han, 2015, p. 8), auto-exploit themselves through the fluidly interchangeable conditions of labor and leisure, hierarchy and autonomy.

\section{A culture of positivity}

As attested by philosopher Byung-Chul Han in his book The Burnout Society, "twenty-first-century society is no longer a disciplinary society, but rather an achievement society" (Han, 2015, p. 8). The 
main characteristic of this achievement society is extreme positivity expressed through overproduction and hyperactivity. A culture of positivity implies that the possibility to do something provokes the actual obligation to do it. Subjects of an achievement society do not distinguish between labor and leisure: all work, no matter what one does. Auto-exploitation is the defining modality of the contemporary achievement society. As Han describes:

The achievement-subject stands free from any external instance of domination forcing it to work, much less exploiting it. It is lord and master of itself. This, it is subject to no one-or, as the case may be, only to itself. It differs from the obedience-subject on this score. However, the disappearance of domination does not entail freedom. Instead, it makes freedom and constraint coincide. Thus, the achievement-subject gives itself over to compulsive freedom - that is, to the free constraint of maximizing achievement. Excess work and performance escalate into auto-exploitation. (Han, 2015, p. 11)

According to the definition of politics constructed by Carl Schmitt, "the specific political distinction to which political actions and motives can be reduced is that between friend and enemy" (Schmitt, 2007, p. 26). While this seems to be a somewhat simplified dichotomy, Schmitt defines enemy in precise terms:

The enemy is not merely any competitor or just any partner of a conflict in general. He is also not the private adversary whom one hates. An enemy exists only when, at least potentially, one fighting collectivity of people confronts a similar collectivity. (Schmitt, 2007, p. 28)

The ultimate consequences of this argument lead to the fact that "a world in which the possibility of war is utterly eliminated, a completely pacified globe, would be a world without the distinction of friend and enemy and hence a world without politics" (Schmitt, 2007, p. 35).

\section{An assembly of independent characters}

The achievement society described by Han is

a society of work in which the master himself has become a laboring slave. In this society of compulsion, everyone carries a work camp inside. This labor camp is defined by the fact that one is simultaneously prisoner and guard, victim and perpetrator. One exploits oneself. It means that 
exploitation is possible even without domination. (Han, 2015, p. 19)

Han's portrayal of the current societal conditions seen through Schmitt's definition of political relationships leads to a space where individuals are driven by their internal compulsion rather than by external conflicts. In a world of achievement-subjects with no friends or enemies, groups of individuals amount to no particular category: they are assemblies of fully independent characters, rendering obsolete the concept of collectivity. The resulting space would look like a kind of menagerie or zoo where there always seems to be a representative-and only one-of all imaginable species.

The new office space here proposed is designed for any and every type of conceivable individual worker: humans (with or without the need for mobility devices), animals (exploited or domesticated), and machines (operated or autonomous). This Office of Diversity is an apparent post-political space where users, as "entrepreneurs of themselves" (Han, 2015, p. 8), perpetually auto-exploit themselves through the fluidly interchangeable conditions of labor and leisure, hierarchy and autonomy. The lack of distinction between labor and leisure results in a chaotic environment that resembles a circus or a modern-day Noah's Ark.

\section{A ramp to nowhere}

In a helicoid, any radial line carries all possible surfaces, from perfectly vertical at the center to absolutely horizontal at the end of an infinite radius (Figure 1). With its ability to encompass all possible surfaces, a helicoid is a self-sufficient enabling of space. Using the helicoid's smooth unfolding of space as its only spatial definition, the Office of Diversity is designed as a continuous unobstructed helicoidal space accessible to all types of workers despite any limitations or preferences that they might exhibit (Figures 2 to 4). The possibility of a human quickly ascending via a stair occurs on the same surface as a robot's need for a reduced slope ramp. 


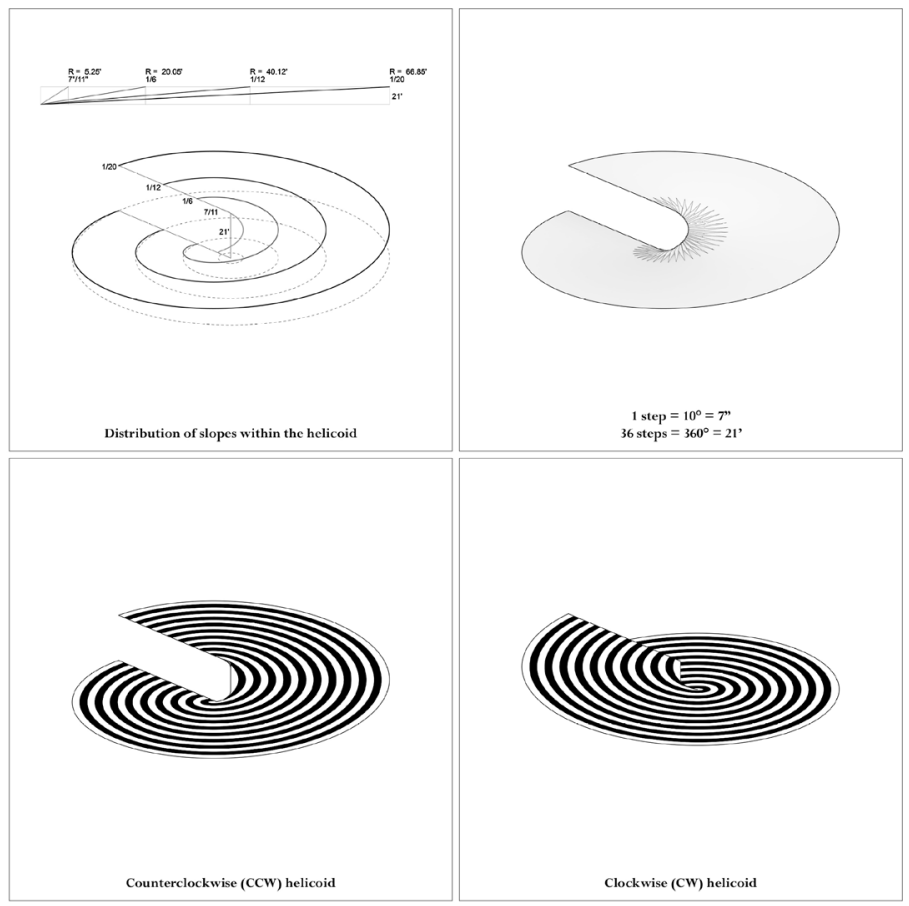

Figure 1

Geometric description of one individual helicoid (Image by author)

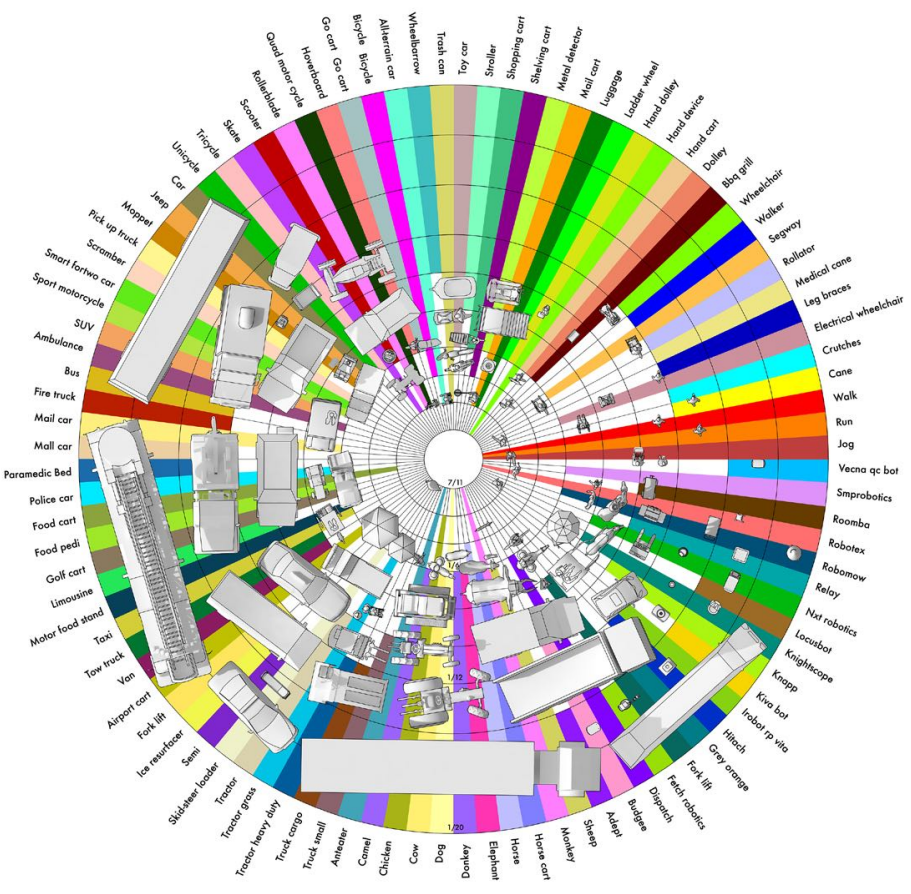

Figure 2

Office workers are located on a helicoid according to their maximum usable slope (Image by author) 
Figure 3

Office workers are categorised by type: vehicles, humans, robots, and animals (Image by author)

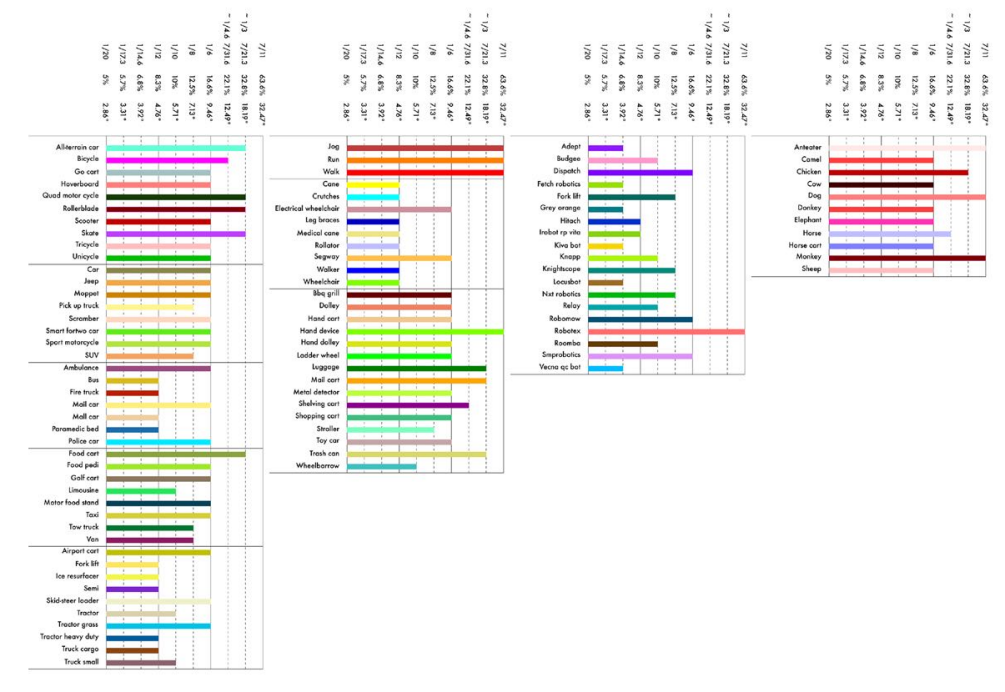

Figure 4

Office workers are classified by the maximum slope they can use (Image by author)

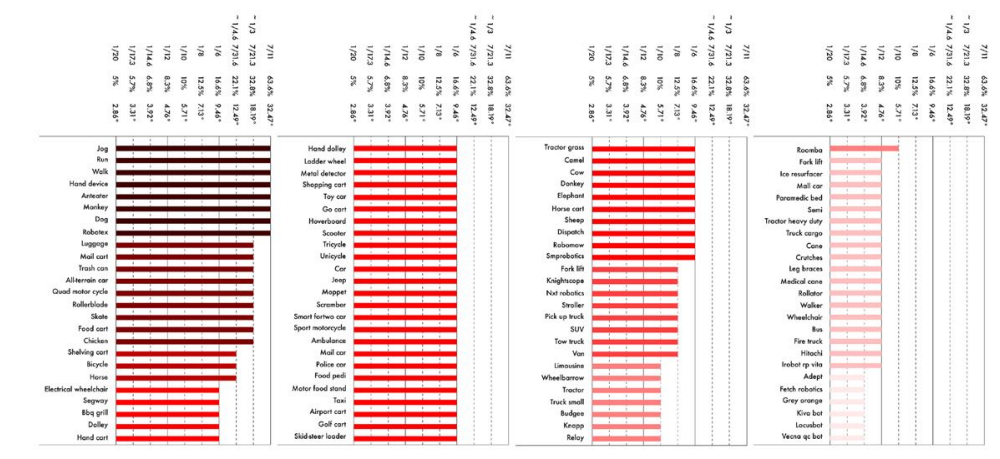

The straight-forward geometric linearity (ascending or descending) of a simple helicoid gets unexpectedly muddled when one or more helicoids intersect. In this case, despite the systematic geometric definition exhibited by a single helicoid, the spaces resulting from two or more intersecting helicoids are disorienting and misleading. The helicoid's initial universal accessibility has become now a labyrinthic structure. Figure 5 illustrates the geometric description of the system used for connecting two helicoids. The X-axis shows varying distances between two helicoids according to the typical ramp slopes used in accessible design $(1 / 6,1 / 12,1 / 20)$. The $Y$-axis shows varying starting angles $\left(0^{\circ}, 45^{\circ}, 90^{\circ}, 135^{\circ}, 180^{\circ}, 225^{\circ}, 270^{\circ}\right.$, $315^{\circ}$ ) for two adjacent helicoids with identical and opposing directions (clockwise, counterclockwise). The Office of Diversity seems to be an enabling structure open to everyone, but, in reality, it is a stalemating structure that leads to nowhere. With this transformation of a helicoid as an inherently limitless surface into 
a confusing spatial organisation, the helicoidal ramp is no longer a means to reach somewhere, but, instead, it has become a place to get lost, a void.

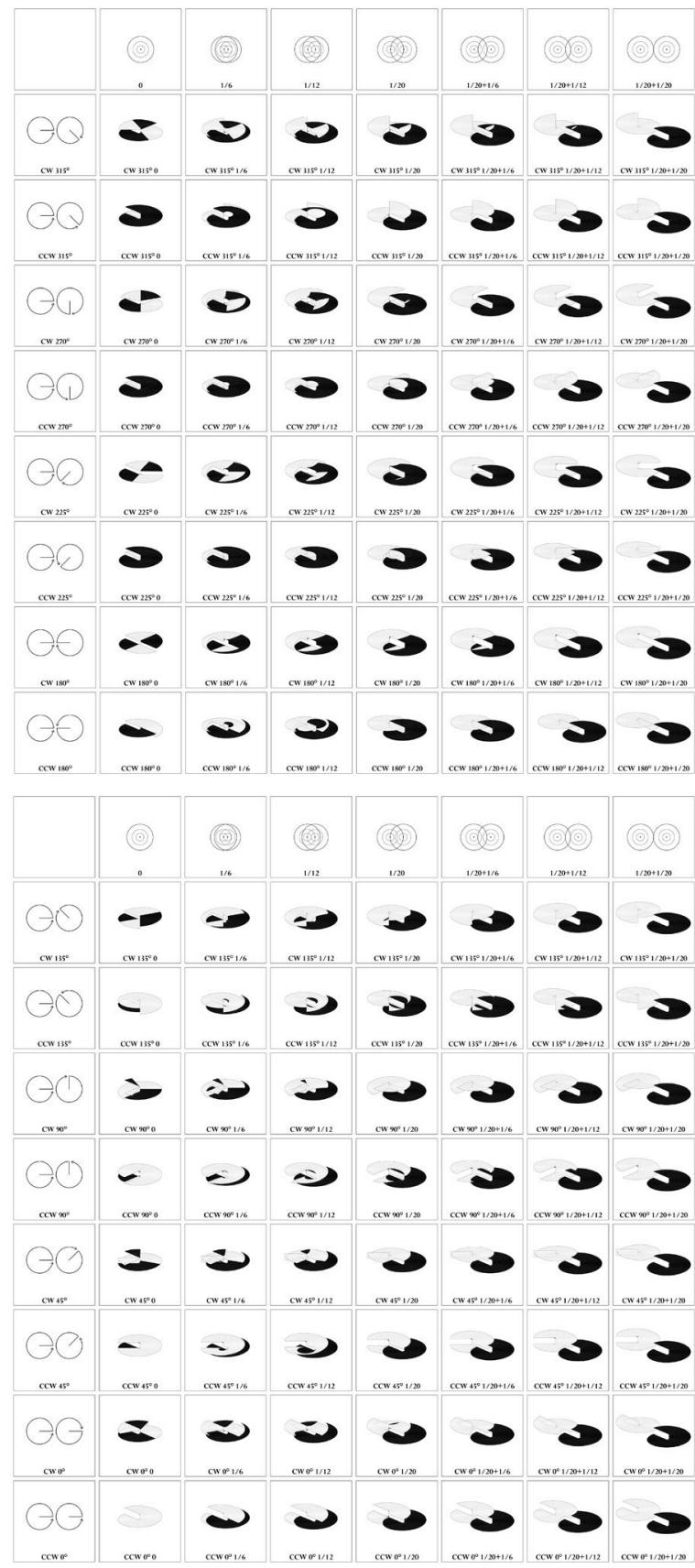

Figure 5

Geometric description of the system used for connecting two helicoids (Image by author) 
This new office type can be understood as a rewriting of Rem Koolhaas' Typical Plan, a text on the American invention of the office building, and a redesign of some of the most significant typical plans accompanying Koolhaas' text (Figures 6 and 7). "The ambition of the Typical Plan is to create new territories for the smooth unfolding of new processes, in this case, ideal accommodation for business" and "its only function is to let its occupants exist. Business can invade any architecture" (Koolhaas, 1995, p. 337). In the achievement society, this ambition and function have been escalated because business is no longer just one possible human activity. Instead, work is now the only compulsion of the achievement-subject.

Figure 6

Examples of reinvented typical plans of the most significant office buildings in New York City ${ }^{3}$ (Image by author)

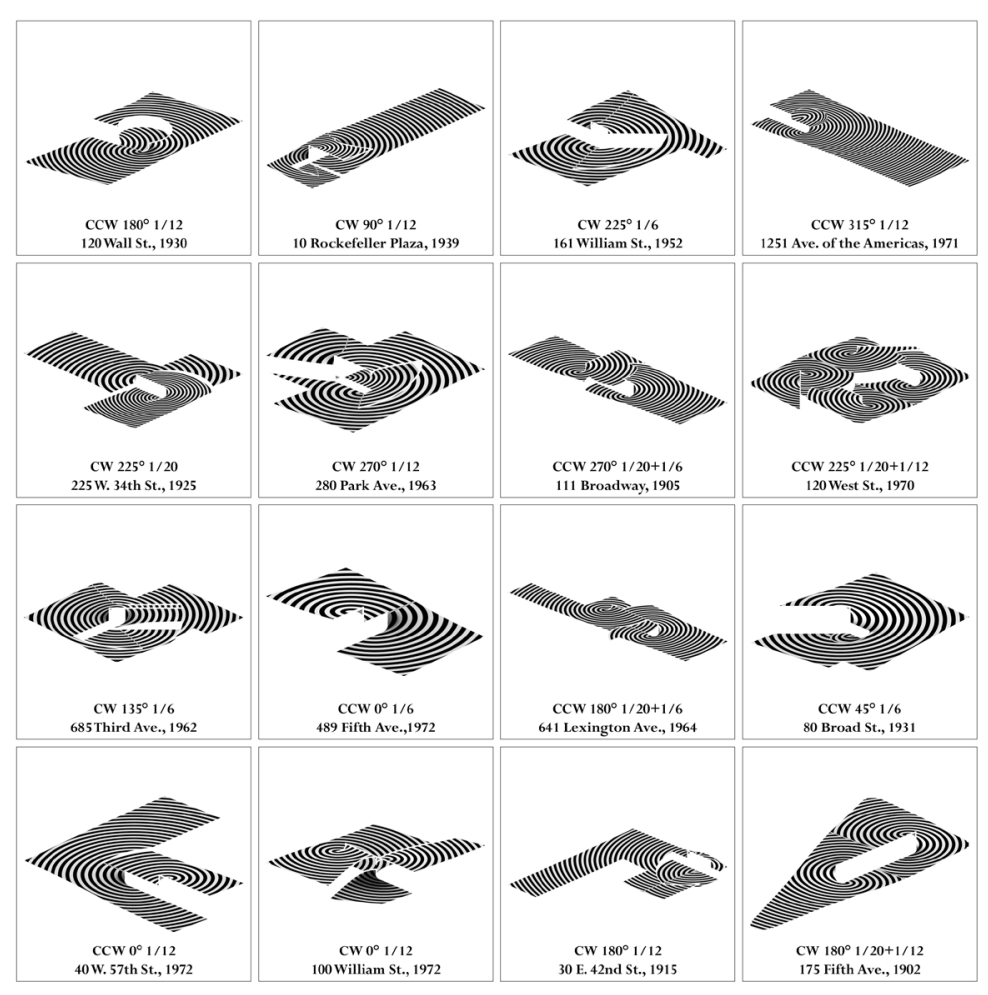

${ }^{3}$ The reader might recognise some of these buildings by their addresses. For example, the Flat Iron building is the one labeled as 175 Fifth Ave., or the Twin Towers are located at 120 West St. 


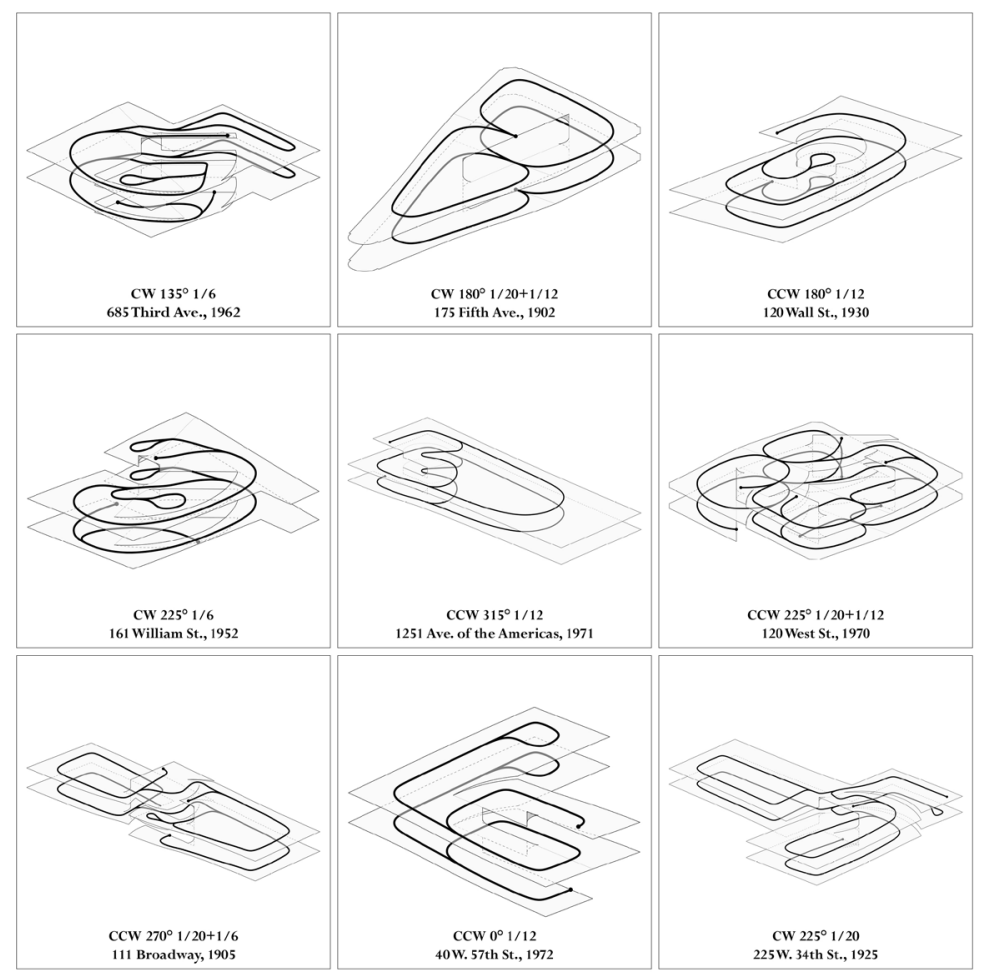

In his text and accompanying plans that survey the most emblematic typical plans of the early twentieth century, Koolhaas describes the modern office building through rapid-fire sets of architectural qualities. Some of these original qualities can be maintained, while others must necessarily be reimagined. For instance, similarly to the Typical Plan described by Koolhaas, the Office of Diversity is both a system and various sets of unique proposals and, therefore, it is "no longer a place but a condition" (Koolhaas, 1995, p. 338). This reimagined office type is no longer "an architecture of the rectangle" (Koolhaas, 1995, p. 338) as the modern office building was, but it is now an architecture of the ramp. While "Typical Plan provides the multiple platforms of 20th-century democracy" (Koolhaas, 1995, p. 337), the office space here proposed provides the continuous helicoids of the 21 st-century auto-exploitation. And so on. This reframing of the typical office plan is showcased in the reconfiguration of two iconic building plans: the Flatiron and the Twin Towers (Figures 8 to 11).
Figure 7

Circulation diagrams of a selected group of reinvented typical plans (Image by author) 
However, the most significant change concerns the aesthetic dimension of this newly imagined building type. Koolhaas portrayed the Typical Plan as "minimalism for the masses" (Koolhaas, 1995, p. 345). But, as Han has shown, the concept of masses does not apply to present society: there are no masses in an achievement society. Under the compulsion of auto-exploitation, achievement-subjects see themselves as unique individuals to be singled out from the crowd: everyone is suffering from a 'Where's Wally' complex. Everyone wants to be Wally. ${ }^{4}$

Figure 8

Plan of the

Flatiron of

Diversity (Image

by author)

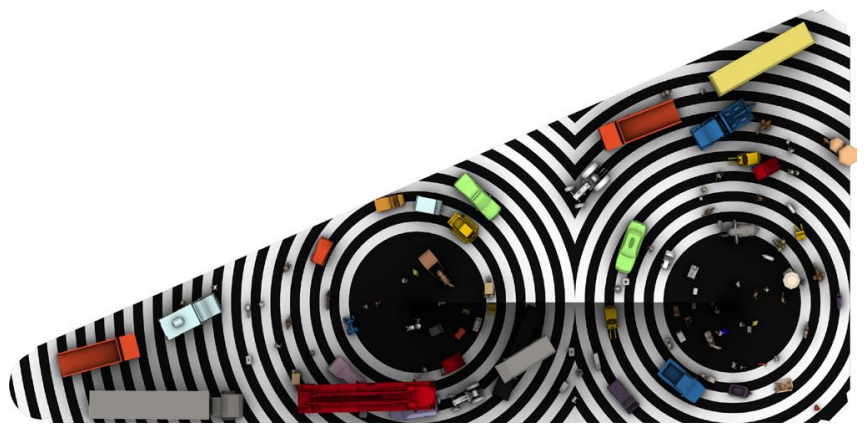

Figure 9

Interior spaces

of the Flatiron of

Diversity (Image

by author)

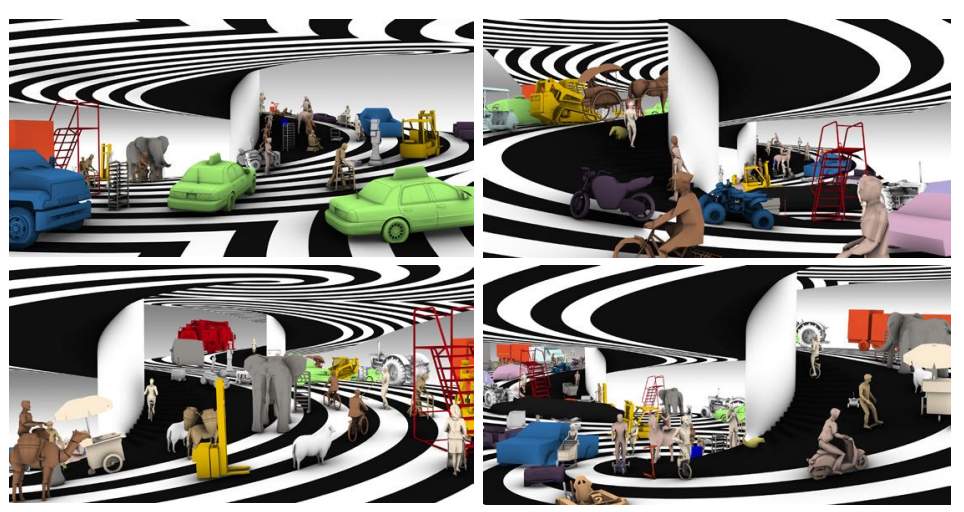

Consequentially, this building type is neither designed for the individual nor the masses. The Office of Diversity is a type designed for Wally, a simple world-and-time-traveler aficionado who has now achieved mythical status. Although some of us might disagree due to his hat style, Wally exemplifies the ordinary person. Nevertheless, he is the perfect expression of the achievement-subject portrayed

${ }^{4}$ While Wally is a white male, I am using him here as a metaphor. With this statement and the writing following it, I am not suggesting in any way that everyone wants to be a white male or that white males are the perfect expression of the achievementsubject portrayed by Han. 
by Han. Wally finds himself in every situation (at work, at play, at war) with the same positive attitude and desire to be called out from the crowd. Despite the diversity of this office space, every one of its subjects has Wally-like aspirations.

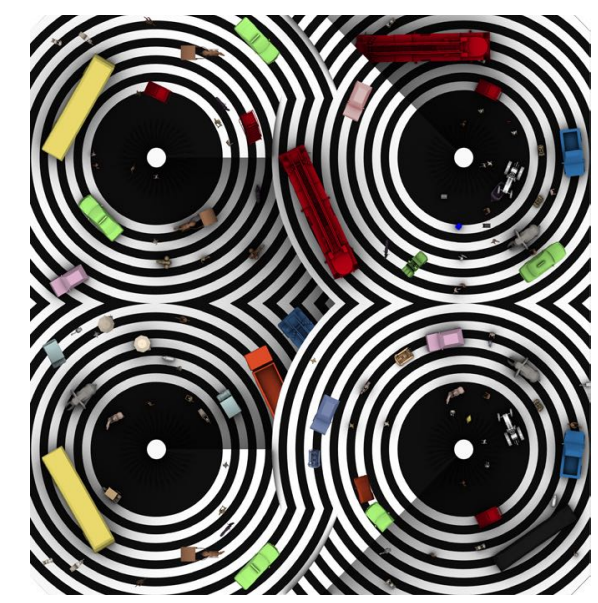

Figure 10

Plan of a Twin

Tower of Diversity

(Image by author)
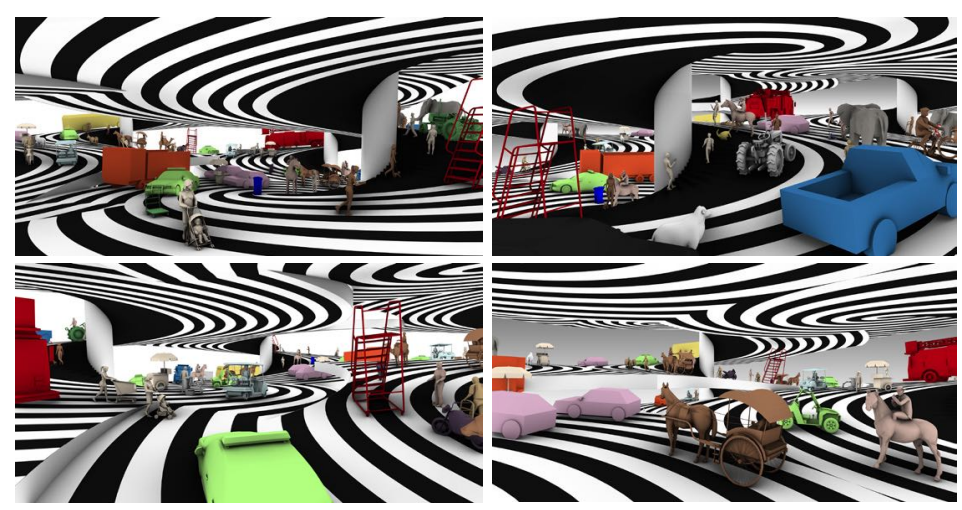

Figure 11

Interior spaces of

a Twin Tower of

Diversity (Image

by author)

\section{Everywhere and From Within}

Hardt and Negri have analyzed previous political strategies as possible alternatives to Empire, from classical local struggles to the "Internationale" (Hardt \& Negri, 2000, pp. 42-63). Since Empire lacks an outside, they conclude that Empire is a regime different from previous ones and, for this reason, none of these historical strategies and tactics are useful anymore. Instead, they argue that "every struggle must attack at the heart of Empire, at its strength" (Hardt \& Negri, 2000, p. 58), implying that "the only strategy available to the struggles is that of a constituent counterpower that emerges from within Empire" (Hardt \& Negri, 2000, p. 59). 
This approach is the one that has been followed in the design of this new type of office. Office of Diversity is a building type designed for the current regime when all subjects have internalised the sociocultural condition lacking an outside. A building type that exposes this ubiquitous condition in an absurd way (a ramp to nowhere) is proposed here as a critical project to open up contemporary space and its subjects. Because it is only when one becomes aware of one's internalised condition that an opening into another reality appears, maybe.

\section{Acknowledgments}

The author initiated this research with a 2010 Junior Faculty Development Fund grant from the School of Architecture and Planning at the University at Buffalo. The study completed during that time was never disseminated, and it has been reused for this project with funding from the Harvard Graduate School of Design. The research has been conducted by the author with Wesley Lam (Bachelor of Science in Architecture student at the University at Buffalo). The design has been completed by the author with Martin Fernandez, Kenneth Hasegawa, and Tammy Teng (Master of Architecture students at the Harvard Graduate School of Design). The text has been written by the author.

\section{References}

Archizoom Associati (2006). No-Stop City: Residential car park universal climatic system. In A. Branzi (Ed.), No-Stop City: Archizoom Associati (pp. 176-179). Hyx.

Condon, P. A. (1994). Built landscape typology: A language of the land we live in. In K. A. Franck \& L. H. Schneekloth (Ed.), Ordering space: Types in architecture and design (pp. 79-94). Van Nostrand Reinhold.

Derrida, J. (1974). Of grammatology. The Johns Hopkins University Press.

Foucault, M. (1979). Discipline and punish: The birth of the prison. Vintage Books.

Grosz, E. (2001). Architecture from the outside: Essays on virtual and real space. MIT Press.

Han, B.-C. (2015). The burnout society. Stanford University Press.

Hardt, M., \& Negri, A. (2000). Empire. Harvard University Press. 
Harvey, D. (1989). The condition of postmodernity: An enquiry into the origins of cultural change. Blackwell.

Jameson, F. (1991). Postmodernism, or, the cultural logic of Late Capitalism. Duke University Press.

Kircher, A. (1675). Athanasii Kircheri è Soc. Jesu Arca Noë. Apud Joannem Janssonium à Waesberge.

Koolhaas, R. (1995). Typical plan. In R. Koolhaas, \& B. Mau (Eds.), S, M, L, XL (pp. 334-353). The Monacelli Press.

Laugier, M.-A. (1755). Essai sur l'architecture. Chez Duchesne.

Meyers, G. E. (2005). Vitruvius and the origins of Roman spatial rhetoric. Memoirs of the American Academy in Rome, 50, 6786.

Moneo, R. (1978). On typology. Oppositions, 13(Summer), 23-45.

Norberg-Schulz, C. (1980). Genius loci: Towards a phenomenology of architecture. Rizzoli.

Quatremère de Quincy, A.-C. (1832). Dictionnaire historique d'architecture. Le Clère et Cie.

Rossi, A. (1982). The architecture of the city. MIT Press.

Schmitt, C. (2007). The concept of the political. University of Chicago Press. 
